American Journal of Economics and Business Administration 3 (3): 444-449, 2011

ISSN 1945-5488

(C) 2011 Science Publications

\title{
Investigating Individuals' Intention to be Involved in Knowledge Management Process
}

\author{
M.J.M. Razi and N.S.A. Karim \\ Department of Information Systems, Kulliyah of Information and Communication Technology, \\ International Islamic University Malaysia 53100, Jalan Gombak, \\ Kuala Lumpur, Malaysia
}

\begin{abstract}
Problem statement: Implementation of Knowledge Management (KM) process in organizations is considered as essential to be competitive in the present competitive world. Though the modern KM practices highly depend on technology, individuals ('organizational members') intention to be involved in KM process plays a major role in the success. Hence, the evaluation of individuals' intention is deemed as significant before the actual implementation of KM process in organizations. Nevertheless, inadequate information is presented in this regard; as a result, a wide research gap prevails in the literature. In this context, the present study focuses on developing a research frame work that can be used to measure the individual intention to be involved in KM process. Approach: Subsequent to a critical analysis of the research gaps, a basic research model has been developed based on knowledge creation theory, KM enablers, and individual acceptance model. Measurers and questionnaire items were identified for each variable from relevant literature. Consequently, the reliability of the instrument was tested among academic staff of a Malaysian university. Results: The Cronbach's alpha for each variable is more than 0.800 that exhibits the reliability of the instruments. Conclusion: The presented research framework might be a doorstep for future study in this area of $\mathrm{KM}$. Moreover, practitioners may use the proposed framework to measure the intention of individuals to be involved in KM process before actually embarking to it. However, the framework and the model should be tested in different socio cultural and organizational climate to make it robust.
\end{abstract}

Key words: Knowledge management process, knowledge creation theory, individual acceptance, Actual Implementation (AI), Theory of Reasoned Action (TRA), Diffusion Of Innovation (DOI), Theory of Planned Behavior (TPB), research framework, performance expectancy

\section{INTRODUCTION}

The business environment has changed over the past decades and the foundation of industrialized economics has shifted from natural resources to intellectual assets. Thus, Knowledge is increasingly becoming the main asset (Kumar and Chhokar, 2011) that contributes to the competitive advantage of many organizations (Christine, 2011). As a consequence, Knowledge Management (KM) processes implementation is wide spread across different sectors in the contemporary knowledge era, starting from IT sector (Nabiollahi et al., 2011) to agricultural sector (Malekmohammadi, 2009). The KM also has been discussed from religious perspective (Yaakub, 2011) and at primary school level (Chongdarakul et al., 2010).

Among the proposed approaches to implement KM process in organizations, a combined approach of personalization and codification is considered appropriate for the success of any organization (Nonaka and Takeuchi, 1995) as KM is considered as a sociotechnical issue (Fatt and Khin, 2010).

Meanwhile, an evaluation of organizational readiness for KM process implementation is suggested before embarking to actual implementation (Holt et al., 2007; Siemieniuch and Sinclair, 2004) as KM process implementation demands some changes in the conduct of organizational activities (Mamaghani et al., 2011) and attitudinal changes of organizational members (Siemieniuch and Sinclair, 2004). The availability of $\mathrm{KM}$ enablers such as KM oriented culture, structure and IT infrastructure is considered as an indication to some extent that the organization is ready to implement $\mathrm{KM}$ process (Holt et al., 2004). Similarly, receptive attitudes of organizational members towards $\mathrm{KM}$ process are also considered as the readiness for KM process (Holt et al., 2007). The present authors believe that the receptive attitudes of individuals in the organization play a major role in the success of KM process as they

Corresponding Author: M.J.M. Razi, Department of Information Systems, Kulliyah of Information and Communication Technology,

International Islamic University Malaysia 53100, Jalan Gombak, Kuala Lumpur, Malaysia 
are the people who initiate and implement it. However, in the light of literature of $\mathrm{KM}$ and individual acceptance models, there are many factors that's might influence the intention of individuals.

In this context, the receptive attitudes of organizational members to be involved in KM process through the availability of resources (KM enablers) can be considered as organizational readiness for $\mathrm{KM}$ process implementation. In other words, the readiness for KM process implementation can be defined as 'the intention to be involved in the $\mathrm{KM}$ process by the organizational individuals within the prevailing organizational context'. KM enablers, (such as KM supportive organizational culture, structure and IT infrastructure) and the factors of individual acceptance, (denoted by performance expectancy of KM and effort expectancy of KM), are expected to be the influencing factors of individuals' intention to be involved in KM process.

An Intensive review of KM literature shows some research gaps in this area of KM. Firstly, limited number of empirical works is available in the literatures which exhibit the limitedness of the literature in this area of KM. Holt et al. (2007) have done a survey study highly depending on change management literature rather than KM literature. Meanwhile, Wei et al. (2009) aimed to assess the organizational readiness for $\mathrm{KM}$ through the level of Perceived Importance (PI) and Actual Implementation (AI) of some KM success factors, KM strategies and KM process, but the study actually evaluates the influence of those factors on organizational performance. In addition to these empirical works, there are few conceptual write-ups such as, Siemieniuch and Sinclair (2004). Therefore, a necessity arises for further studies on this area of KM.

Secondly, KM literature reveals some organizational factors which are considered as preconditions for a successful KM process implementation. Different kinds of terms have been used to symbolize these factors. For example; KM infrastructure (Becerra-Fernandez et al., 2004), organizational knowledge capabilities (Yang and Chen, 2007) and KM capabilities (Lee and Lee, 2007). In general, all these studies exhibit the socio-technical nature of KM and mainly focused on KM supportive organizational culture, organizational structure and IT infrastructure for KM process implementation. However, these factors have not been considered comprehensively in the previous studies, thus a need comes up to formulate a research framework involving these KM enablers as well.

Thirdly, there are many theories in the Information Systems (IS) literature which stress the importance of individual acceptance for any organizational change. For example, Theory of Reasoned Action (TRA), Diffusion Of Innovation (DOI), Theory of Planned Behavior (TPB), Technology Acceptance Model (TAM), Unified Theory of Acceptance and Use of Technology (UTAUT) and so on. Therefore, an allinclusive research framework to measure individuals' intention for KM should be proposed considering the factors of individual acceptance too.

Finally, knowledge creation theory introduced by Nonaka and Takeuchi (1995), which consists of the processes of socialization, externalization, combination and internalization, is sighted as the basic process for knowledge creation and sharing in the KM literature (Becerra-Fernandez et al., 2004; Stevens et al., 2010). In addition, the importance of this basic process is acknowledged in the literature (Nonaka et al., 1994; Nonaka and Takeuchi, 1995). There are number of empirical studies on KM process (such as, Nonaka et al., 1994; Choi and Lee, 2002) based on this process in the past. However, the previous researchers on organizational readiness for KM have not considered this process in their studies. Hence, a need arises to accommodate this process in the research framework. Considering the above mentioned gaps in the KM literature a comprehensive research model to evaluate individuals' intention to be involved in $\mathrm{KM}$ process implementation is proposed as follow.

\section{MATERIALS AND METHODS}

The initiation for $\mathrm{KM}$ process implementation should come from the organizational members (Siemieniuch and Sinclair, 2004; Choi et al., 2008), thus their willingness (intention) to be involved in $\mathrm{KM}$ process should be investigated. The intention to be involved in KM process can be assessed based on KM sub process (socialization, externalization, combination and internalization) as those are the route process of knowledge creation and sharing (Becerra-Fernandez et al., 2004). The KM sub process is considered as the way to implement $\mathrm{KM}$ process in organizations.

Meantime, the availability of KM enablers shows that the organization is ready for KM process implementation to some extent (Holt et al., 2004). Literature on KM enablers (Lee and Lee, 2007; Becerra-Fernandez et al., 2004; Yang and Chen, 2007) demonstrate that $\mathrm{KM}$ enablers provide a conducive environment for organizational members to implement KM process. Therefore, it can be expected that those KM enablers may influence the intention of organizational members to be involved in KM process. Similarly, literature on individual acceptance (TAM, 
UTAUT) substantiates that performance expectancy and effort expectancy influence the behavioral intention of individuals. In this perspective, it can be assume that the factors of individual acceptance also may influence on the intention of organizational members to be involved in KM process. Based on the above discussion, a basic research model has been proposed in Fig. 1.

The model is developed based on the theories of TRA and TPB which explain that an intention leads to behavior. The model was conceptualized based on the studies of Choi et al. (2008), Lee and Lee (2007), Wei et al. (2009), Lin (2007), Venkatesh and Morris (2003) and Choi and Lee (2002). Most of these frameworks were developed based on the theory of knowledge creation and the KM enablers.
Three factors of KM enablers were found worth exploring namely, organizational culture (Choi et al., 2008; Lee and Lee, 2007; Wei et al., 2009; Lin, 2007), organizational structure (Lee and Lee, 2007; Lin, 2007) and IT infrastructure (Lee and Lee, 2003; Lin, 2007). In addition, based on the theories of TRA, TPB, TAM, and UTAUT the factors of individual acceptance, namely performance expectancy of KM (Venkatesh and Morris, 2003) and effort expectancy of KM (Venkatesh and Morris, 2003) were established. Furthermore, the factors of intention to be involved (Choi and Lee, 2002) were recognized based on knowledge creation theory (Nonaka et al., 1994).

Table 1 shows the operational definition, the source of measurement and questionnaire items for each variable in the model.

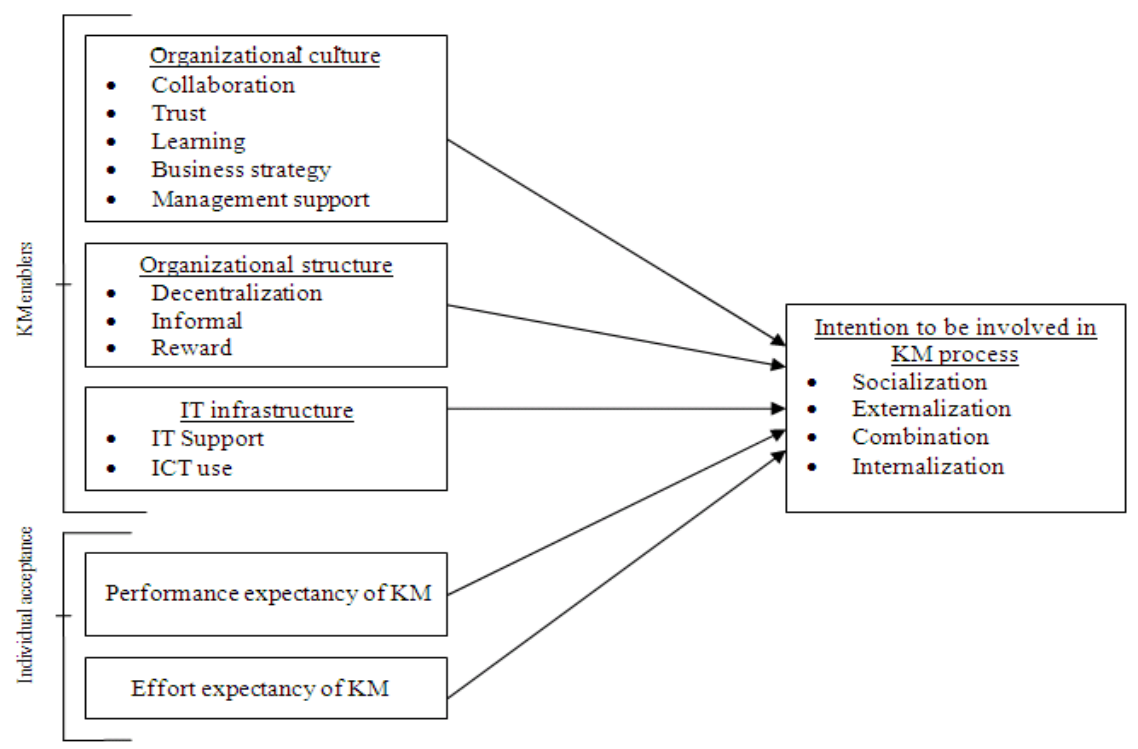

Fig. I: Basic research model

Table 1: Operational definition, source of measurement, and questionnaire items for each variable

\begin{tabular}{|c|c|c|c|}
\hline Variables & Operational definition & $\begin{array}{l}\text { Source of } \\
\text { measurement }\end{array}$ & Items \\
\hline Collaboration & $\begin{array}{l}\text { Degree of active support and helps } \\
\text { among colleagues with in the } \\
\text { organization. }\end{array}$ & & $\begin{array}{l}\text { Colleagues in my organization are supportive. } \\
\text { I am satisfied by the degree of collaboration among colleagues in } \\
\text { my organization } \\
\text { I wish to collaborate across organizational units within my } \\
\text { organization } \\
\text { I wish to accept responsibility for failure }\end{array}$ \\
\hline Trust & $\begin{array}{l}\text { Degree of reciprocal faith among the } \\
\text { colleagues in terms of intention and } \\
\text { behavior within the organization. }\end{array}$ & Choi et al. (2008) & $\begin{array}{l}\text { I believe colleagues in my organization are honest and reliable. } \\
\text { I believe colleagues in my organization treat others reciprocally } \\
\text { I believe colleagues in my organization are knowledgeable and } \\
\text { competent in their area. } \\
\text { I believe colleagues in my organization will act towards the } \\
\text { best interest of the organizational goals. }\end{array}$ \\
\hline Learning & $\begin{array}{l}\text { Degree of opportunity, variety, } \\
\text { satisfaction and encouragement for } \\
\text { learning and development within the }\end{array}$ & Lee and Lee (2007) & $\begin{array}{l}\text { My organization provides various formal training } \\
\text { My organization provides opportunities for informal } \\
\text { individual development other than formal training. }\end{array}$ \\
\hline
\end{tabular}


Am. J. of Economics and Business Administration 3 (3): 444-449 2011

Table 1: Continue

organization

Business strategy Degree of link between organizational strategy and KM strategy

Top management Degree of support from top managers support

for KM through providing guidance and necessary resources
Wei et al. (2009)

Lin (2007)

Lin (2007)

Degree of relevancy between the rewarding system and the involvement in $\mathrm{KM}$ process.
IT Support

Degree of availability of IT support for KM process initiatives within the organization.
Lee and Lee

(2007)

Lin (2007) technology by the individuals in the organization for KM initiatives.
My organization encourages people to attend seminars, symposia and so on.

My organization provides various programs such as clubs and community gatherings.

I am satisfied with the contents of job training or self-

development programs.

I understand the importance of knowledge. My organization formulates strategic plans for knowledge creation and sharing.

My organization has specific objectives for knowledge creation and sharing.

My organization's mission statement reflects the importance of knowledge creation and sharing

My senior managers always support the knowledge creation and sharing initiatives.

My senior managers provide necessary help and resources for knowledge creation and sharing initiatives.

My senior managers are keen to see my involvement in knowledge creation and sharing initiatives.

Lee and Lee (2007) I can make decisions without approval.

I am encouraged to make my own decisions.

I do not need to refer to some one else.

I can take action without a supervisor.

There are many activities in my organization that are not covered by formal procedures.

I can ignore the rules and handle some situation informally in my organization.

Rules and procedures are not that emphasized in my organization. I can make my own rules on my job.

My organization provides higher salary in return for my contribution to knowledge creation and sharing.

My organization provides higher bonus in return for my contribution to knowledge creation and sharing.

My organization provides promotions in return for my contribution to knowledge creation and sharing.

My organization provides increased job security in return for my contribution to knowledge creation and sharing.

My organization provides IT support for collaborative works regardless of time and place.

My organization provides IT support for communication among colleagues in my organization.

My organization provides IT support for simulation and prediction.

My organization provides IT support for systematic storing of valuable records.

My organization provides IT support for searching necessary information and sharing it with others

I use electronic storage (such as online data base and data warehousing) extensively to access knowledge.

I use knowledge networks (such as groupware, intranet, virtual communities, etc.) to communicate with colleagues.

I use the technology to share knowledge with colleagues in my organization.

I use the technology to share knowledge with other persons out side the organization.

I would find creation and sharing of knowledge useful in my job.

Creation and sharing of knowledge would enable me to accomplish task more quickly.

If I involve with knowledge creation and sharing initiatives, it will increase my chances of getting a better pay.

Creation and sharing of knowledge would enhance my productivity.

Effort Degree of ease associated with the Al-Gahtani et al. (2007)
My role in knowledge creation and sharing process would be clear and understandable. It would be easy for me to become skillful in knowledge creation 
Socialization $\begin{aligned} & \text { Degree to which the individuals in } \\ & \text { the organization intend to be }\end{aligned}$ involved in socialization process

Externalization Degree to which the individuals in the organization intend to be involved in externalization process

Combination

Degree to which the individuals in the organization intend to be involved in combination process

Internalization

Degree to which the individuals in the organization intend to be involved in internalization process and sharing initiatives

Learning the initiatives of creation and sharing of knowledge would be easy for me.

I would find the involvement in the process of knowledge creation and sharing be easy.

Choi and Lee I intend to be involved in gathering information and experiences (2002) from others within my organization.

I intend to be involved in sharing information and experiences with others within my organization.

I intend to be engaged in dialogue with competitors.

I intend to be involved in finding new strategies and opportunities inside the organization.

I intend to be involved in creating a study environment that allows colleagues to understand the craftsmanship and expertise.

Choi and Lee I intend to be involved in creative dialogues with colleagues.

(2002) I intend to use deductive (top down) and inductive (bottom up) thinking for strategy formulation.

I intend to use metaphors (images/description) in dialogue for concept creation.

I intend to exchange various ideas with colleagues.

I intend to provide subjective opinions in dialogues.

Choi and Lee I intend to use published literature, computer simulation and

(2002) forecasting to formulate strategies.

I intend to create documents on product and services

I intend to create databases on product and services

I intend to build up materials by gathering literature and technical information.

Choi and Lee I intend to be involved in liaisoning activities with other (2002) departments by developing cross functional teams.

I intend to be involved in setting teams as a model for conducting experiments and sharing results with entire departments.

I intend to be involved in searching and sharing new values and thoughts with colleagues.

I intend to share and try to understand management vision through communications with colleagues.
Table 2: Reliability of instruments

\begin{tabular}{llll}
\hline Measures & Cronbach's & Cronbach's \\
Alpha & Measures & Alpha \\
\hline Rewards & 0.965 & Business strategy & 0.885 \\
Effort expectancy & 0.947 & Learning & 0.881 \\
IT Support & 0.930 & Collaboration & 0.878 \\
Performance expectancy & 0.913 & Trust & 0.875 \\
Decentralization & 0.912 & ICT Use & 0.868 \\
Management Support & 0.902 & Socialization & 0.829 \\
Externalization & 0.888 & Internalization & 0.820 \\
Informal & 0.887 & Combination & 0.800 \\
\hline
\end{tabular}

\section{RESULTS}

A questionnaire was prepared using seven levels of Likert scale ranking from strongly disagree to strongly agree to measure the reliability of the instruments. 120 questionnaires were distributed among academic staff of a Malaysian university, out of which 46 were returned in a useable condition, making the response rate $38 \%$. Cronbach's alpha was calculated using SPSS. The results are shown in Table 2. The Cronbach's alpha value is more than 0.800 for each variable which demonstrate the high reliability of the instruments.

\section{DISCUSSION}

The framework can be a starting point for future works in this area of KM. In addition, the proposed research instrument can be used by practitioners who plan to implement $\mathrm{KM}$ process, to measure the organizational members' intentions to be involved in $\mathrm{KM}$ process. Based on the findings, they can formulate implementation strategies.

\section{CONCLUSION}

The research framework presented might be one of the prime attempts in this area of research. As limited writings are available on KM readiness any effort with empirical component that would enrich the literature might be considered as a valuable contribution. However, the research framework should be applied in different socio cultural environment and at different organizational context to make it robust model. 
Am. J. of Economics and Business Administration 3 (3): 444-449 2011

\section{REFERENCES}

Al-Gahtani, S., G. Hubona, and J. Wang, 2007. Information Technology (IT) in Saudi Arabia: Culture and the acceptance and use of IT. Inform. Manage., 44: 681-691. DOI: 10.1016/J.IM.2007.09.002

Becerra-Fernandez, I. A. Gonzalez and R. Sabherwal, 2004. Knowledge Management: Challenge, Solutions and Technologies. 1st Edn., Upper Saddle River, Prentice Hall, New Jersey, ISBN: 013-101606-7, pp: 386.

Choi, B. and H. Lee, 2002. Knowledge management strategy and its link to knowledge creation process. Exp. Syst. Appl., 23: 173-187. DOI: 10.1016/S0957-4174(02)00038-6

Choi, S.Y., Y.S. Kang and H. Lee, 2008. The effects of socio-technical enablers on knowledge sharing: An exploratory examination. J. Inform. Sci., 34: 741-754. DOI: 10.1177/0165551507087710

Chongdarakul, S., S. Chankajon and R. Supapongpichait, 2010. Thai local entertainment of local community in Mae-Klong river Basin: Knowledge Management for inheriting local culture of primary school. J. Soc. Sci., 6: 439-442. DOI: $10.3844 /$ jssp.2010.439.442

Christine, N.L.T., 2011. Knowledge management acceptance: Success factors amongst small and medium-size enterprises. Am. J. Econ. Bus. Admin., $3: \quad 73-80 . \quad$ DOI: 10.3844/ajebasp.2011.73.80

Fatt, C.K. and E.W.S. Khin, 2010. The social-technical view of knowledge management in services industries. J. Soc. Sci., 6: 256-264. DOI: 10.3844/jssp.2010.256.264

Holt, D.T., S.E. Bartczak, S.W. Clark and M.R. Trent, 2004. The development of an instrument to measure readiness for knowledge management. Proceeding of the 37th Hawaii International Conference on System Science, Jan. 5-8, IEEE Computer Society, Big Island, Hawai, USA., pp: 16. DOI: 10.1109/HICSS.2004.1265575

Holt, D.T., S.E. Bartczak, S.W. Clark and M.R. Trent, 2007. The development of an instrument to measure readiness for knowledge management. Knowl. Manage. Res. Pract., 5: 75-92. DOI: 10.1057/PALGRAVE.KMRP.8500132

Kumar, P. and S. Chhokar, 2011. An approach from knowledge dust to gems (knowledge management). J. Comput. Sci., 7: 298-303. DOI: 10.3844/jcssp.2011.298.303

Lee, Y.C. and S.K. Lee, 2007. Capabilities, processes and performance of knowledge management: A structural approach. Hum. Factors Ergon. Manufact., 17: 21-41. DOI: 10.1002/HFM.20065
Lin, H.F., 2007. Knowledge sharing and firm innovation capability: An empirical study. Int. J. Manpower, 28: 315-332. DOI: $10.1108 / 01437720710755272$

Malekmohammadi, I. 2009. Interpretive perspective of knowledge management stance in agricultural knowledge information system to fostering research/extension linkage. Am. J. Agric. Biol. Sci., $\quad 4$ : 230-241. 10.3844/ajabssp.2009.230.241

Mamaghani, N.D, R. Samizadeh and F. Saghafi, 2011. Evaluating the readiness of iranian research centers in knowledge management. Am. J. Econ. Bus. Admin., 3: 203-212. DOI: 10.3844/ ajebasp.2011.203.212

Nabiollahi, A., R. A. Alias and S. Sahibuddin, 2011. Involvement of service knowledge management system in integration of ITIL V3 and enterprise architecture. Am. J. Econ. Bus. Admin., 3: 165170. DOI: $10.3844 /$ ajebasp.2011.165.170

Nonaka, I. and H. Takeuchi, 1995. The Knowledge Creating Company. 1st Edn., University Press, Oxford, ISBN: 0-19-509269-4, pp: 10-20.

Nonaka, I., P. Byosiere, C.C. Borucki and N. Konno, 1994. Organizational knowledge creation theory: A first comprehensive test. Int. Bus. Rev., 3: 337-351. DOI: 10.1016/0969-5931(94)90027-2

Siemieniuch, C.E. and Sinclair, 2004. A framework for organizational readiness for knowledge management. Int. J. Operat. Produc. Manage., 24: 79-98. DOI: $10.1108 / 01443570410511004$

Stevens, R.H., J. Millage and S. Clark, 2010. Waves of knowledge management: The flow between explicit and tacit knowledge. Am. J. Econ. Bus. Admin., 2: 129-135. DOI: 10.3844/ ajebasp.2010.129.135

Wei, C.C., C.S. Choy and W.K. Yew, 2009. Is the malaysian telecommunication industry ready for knowledge management implementation. J. Knowl. Manage., $\quad$ 13: $\quad 69-87 . \quad$ DOI: $10.1108 / 13673270910931170$

Yaakub, M.B.H. 2011. Islamic conceptualisation of knowledge management. Am. J. Econ. Bus. Admin., 3: 363-369. DOI: 10.3844/ ajebasp.2011.363.369

Yang, C. and L.C. Chen, 2007. Can organizational knowledge capabilities affect knowledge sharing behavior? J. Inform. Sci., 33: 95-109. DOI: $10.1177 / 0165551506068135$ 